\title{
CCMS Model - a Novel Approach to Digitalization Level Assessment for Manufacturing Companies
}

\author{
Gábor Nick ${ }^{1,2}$, Ádám Szaller ${ }^{1,3}$ and Tamás Várgedo" ${ }^{1}$ \\ ${ }^{1}$ Institute for Computer Science and Control, Budapest, Hungary \\ ${ }^{2}$ EPIC InnoLabs Ltd. Budapest, Hungary \\ ${ }^{3}$ Department of Manufacturing Science and Engineering, Faculty of Mechanical Engineering, Budapest University \\ of Technology and Economics, Budapest, Hungary \\ gabor.nick@epicinnolabs.hu \\ adam.szaller@sztaki.hu \\ vargedo.tamas@sztaki.hu
}

\begin{abstract}
Today, a significant number of different models and methods are available to assess the readiness of industrial companies concerning Industry 4.0 implementation. In this respect, the SMEs are in the most vulnerable position. Thus, there is a need for a critical review and analysis of the existing models' fit while recognizing the specific requirements of this type of enterprise. The results of a study that has become a point of reference (Mittal 2018) show that only a limited number of the smart manufacturing and Industry 4.0 roadmaps, maturity models, frameworks, and readiness assessments available today reflect at least partly the specific requirements and challenges of SMEs. In this paper, an attempt is made to introduce a solution to mitigate this gap, that considers cultural and location-specific, ecosystem-related restrictions or influences (macro-level view) and particular company-level aspects (micro-level view), as well.

The CCMS (Company CoMpaSs) model developed by EPIC InnoLabs is based on an online survey and considers both business and technological views. The answers given by the respondent company are weighted, and intervention points are selected from a predefined set of eight elements per dimension, on the basis of analyzing the responses (coming from different areas). The output of the model (besides the statistical evaluation of the results like comparisons to averages derived from metadata) is a prioritized list of intervention points that shows the most important fields of action for the respondent on an interactive dashboard. The applied weightings are determined by the model creators and result from the inherent structure of the model. The questions and the weights can also be changed as the used technologies evolve. CCMS provides a quick (meaning that the respondent gets prompt results), low-risk, online maturity assessment for manufacturing SMEs, which helps decision-makers to determine target maturity levels in different fields.
\end{abstract}

Keywords: Industry 4.0; Maturity model; readiness assessment; intervention points, digitalization

\section{Introduction}

\subsection{Industry 4.0 and challenges for SMEs}

The development of Industry 4.0 is continuous and provides an ever wider variety of options for digital transformation and interconnected technologies. Hence, most organizations have to face the problem of how to define their role within the field and to decide on the necessary Industry 4.0 measures that will best match their company's needs. Many academic institutions, industrial federations, and professional organizations have developed Industry 4.0 maturity models to support companies in their effort to assess their current status within the Industry 4.0 context. These maturity models differ substantially in their approach, structure, and complexity. Some perform the appraisal of a company's Industry 4.0 maturity grade by merely filling in a (mostly online) survey. Others, however, include more steps with direct interactions with the respondent, such as on-site interviews and workshops with the staff, too. The overall experience of today's situation is that due to the high number of Industry 4.0 maturity models, it is not straightforward at all for companies to choose the model that will fit them best (Leineweber et al., 2018).

As Erol, Schumacher and Sihn (2016) mention, one of the main problems regarding Industry 4.0 is the lack of understanding of the particular relevance and benefit of the whole concept. Therefore, companies require guidance on their road towards digitalization and how they could make the best use of external expertise that extends beyond them. It should help them to determine the action fields where they should start the transformation process. Otherwise, isolated solutions may come to life - the most common example of this is focusing on just the technological aspects and ignoring, for example, the human factor. Assuming that Industry 4.0 is to be achieved by simply buying robots and making machines smarter is often a problem, according to the authors' industrial experience. 
Nevertheless, the decisions in connection with Industry 4.0 and digitalization are also strongly affected by the infrastructure of the local environment, available R\&D\&I services, the legal and business environment (macrolevel aspects). Paying too little attention to the organization's external environment is a common mistake coded in many Industry 4.0 maturity models and readiness assessments as well. The vast majority of these models are focusing on the micro-level aspect only by assessing the company and its inner processes in detail.

In contrast to this, the Industry 4.0 maturity model described by Nick et al. (2019b) uses an ecosystem-based approach and takes into consideration general information about the participating organization, the relevant company level Industry 4.0 maturity topics (micro-level), and issues related to the national economic policy (macro-level) as well. Like Nick et al. (2019a) mention, countries have different goals since their status is not the same regarding digitalization. Thus, the companies located in separate countries could have different legal environments, local infrastructure, and possibilities that are affecting the decision-making process concerning Industry 4.0 investments. These two papers also show that considering the local climate, region-specific endowments (e.g., availability of skilled workforce, government funding, etc.) are essential and should be examined when determining the first and then subsequent steps towards digitalization.

\subsection{Existing models}

In this paper, the goal is not to make an extensive literature review on existing models and readiness assessment methods, as it has been done by others, for example, Leyh, Schäffer and Forstenhäusler (2016), Marheine, Gruber and Back (2019), Leineweber et al. (2018) and Nick et al. (2019a). Mittal et al. (2018) made a critical literature review on smart manufacturing and Industry 4.0 roadmaps, maturity models, frameworks, and readiness assessments available today. They concluded that only a limited number of them reflect at least partly the specific requirements and challenges of SMEs (generally, they are focusing on solutions for MNEs). Earlier, Puchan, Seif, and Mayer in their study (2015) did not find any models related to Industry 4.0 that addressed the entire value chain of a company. Today the statement is no longer valid as numerous models with a broad spectrum of new considerations have been developed by universities, research institutes, and consultancies for instance, Fraunhofer Austria, 2020; Schuh et al., 2017. As the paper focuses on introducing a novel proprietary maturity model, here, we confine only to some examples for the different model types and categories.

As for the evaluation method, some models use self-assessment as an input, while other ones include workshops, too, or an audit done by external experts. There is also a solution that requires the least financial and work effort, time, and implied risk - its input is an online survey (with different levels of result elaboration for each model). For instance, two examples of short self-assessment models designed for small and mediumsized engineering companies are developed by the German Engineering Federation (VDMA). One is the Industry 4.0 Readiness model by the IMPULS Foundation, and the second is a visual toolbox outlined in the paper Guideline Industry 4.0, by the same federation (IMPULS, 2020; VDMA and Partners, 2016)

The two models CCMS and the Industry 4.0 migration model developed for the ADAPTION project (Leineweber et al., 2018) are also based on a digital self-assessment, but address socio-technical aspects and personnelrelated topics in more detail. The Fraunhofer Austria Industry 4.0 Maturity Model (Fraunhofer Austria, 2020) Pathfinder i4.0 (Innovatioszentrum für Industrie 4.0., 2020), and Industry 4.0 Maturity Index (Schuh et al., 2017) are more complex models, they all include at least one on-site workshop in the assessment process.

Models can also be distinguished regarding their aim and focus: some of them are profit-oriented (Fraunhofer Austria, 2020; Schuh et al., 2017; Innovatioszentrum für Industrie 4.0., 2020; CCMS), others aim to generate conclusions about the status of the companies to enlarge a knowledge base (Nick et al., 2019b), while models in a third group address both goals (Schuh et al., 2017). In general, maturity models compare the present state of a company to some baseline: this could be aligned either to the most common pattern of answers to the given questionnaire (Nick et al., 2019b), or the respondent's target maturity level (Fraunhofer Austria, 2020), or the model developer's view on the best practice (CCMS). There are models whose method is to obtain a single, global perspective on a company (Nick et al., 2019b), and others that aim to get multiple opinions from the respondents of the evaluated company as many different perspectives may exist in parallel (Fraunhofer Austria, 2020; Schuh et al., 2017; Innovatioszentrum für Industrie 4.0., 2020; CCMS).

In this paper, the CCMS model is presented to offer an affordable, quick, low-risk Industry 4.0 assessment tool that helps SMEs in the manufacturing industry to determine intervention points to attain their digitalization goals. This model has several features that are novelties:

- Instead of comparing the as-is results of the online survey to a target (to-be) status defined in advance by the respondent's company, it uses a baseline determined by the model creators (who are 
experts with broad industrial experience).

- Instead of showing only statistical results after completing the survey, it provides a prioritized intervention point list that specifies the most important fields where the company has to develop itself.

- Takes two aspects into consideration simultaneously: the technological and the business views, representing the respondent's employees with different perspectives who have to answer questions according to their role in the company.

- Integrates micro-level (internal details of the company and its production) and macro-level (local environment) aspects, and this way uses an ecosystem approach to determine the results.

\section{CCMS Model}

The aim of the CCMS model developed by EPIC InnoLabs is to synthesize and report on the responses of an increasingly wide selection of industry representatives, both in terms of revealing internal contradictions and in terms of a proposed target system based on scientific aspects. The purpose of the representative survey is to encompass the entire Industry 4.0 ecosystem of a company that intends to be digitally transformed. Weighting each sub-area provides a basis for the formulation of a strategy that incorporates the organization's industrial digitization efforts. Using a hierarchical, top-down approach, the model is also suitable for simultaneously integrating the inputs of key players who represent the horizontal approach of company management, i.e., both the technological and business aspects.

The model is based on pillars built on dimensions (see Figure 1). These pillars respectively represent different aspects of industrial digitization. Under the dimensions, intervention points were identified. The maturity level of the latter is calculated using predefined questions. Indeed, the response(s) to each question determine(s) the digital readiness of the organization for that particular intervention point. Since respondents fundamentally have two different approaches and background knowledge of the organization, technological and businessoriented questions are also included to conclude to valuable intervention points.

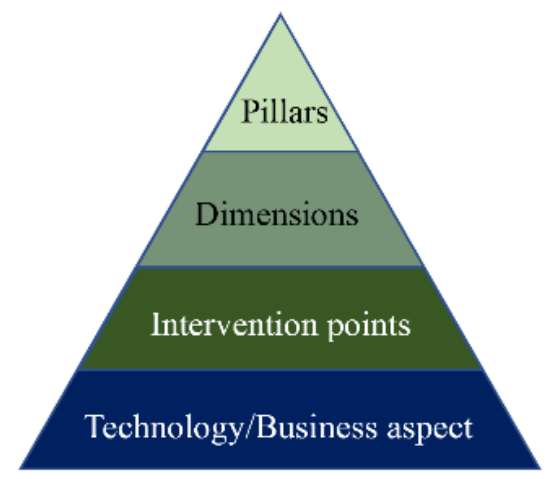

Figure 1: Model approach

The model rests on three pillars: Ecosystem, Value Creation, and Value. By definition, the essence of industrial digitization is the close intertwining of the Real and Virtual world, with a focus on the Human. These three dimensions characterize the Value Creation pillar, where the inputs are transformed into the desired output. The Data flowing between these three create an inseparable connection, from which as an intermediate, Information and, at the very end, Knowledge emerges. Input resources provided by the Ecosystem pillar include the organization's Strategy and all Local Resources (e.g., infrastructure elements, legal environment, etc.). On the output side, the Value (third pillar) the companies generate appears in the form of smart Products and Services. The Value Chain dimension implements horizontal integration, which in turn deals with suppliers, business partners, and customers. The connection between the different pillars, dimensions, and aspects are depicted in Figure 2, where dimensions pertaining to the same pillar are marked with varying shades of the same colour (Value - teal, Ecosystem - green, Value Creation - blue).

In the following subsections, the pillars of the model and the dimensions are introduced in more detail. 


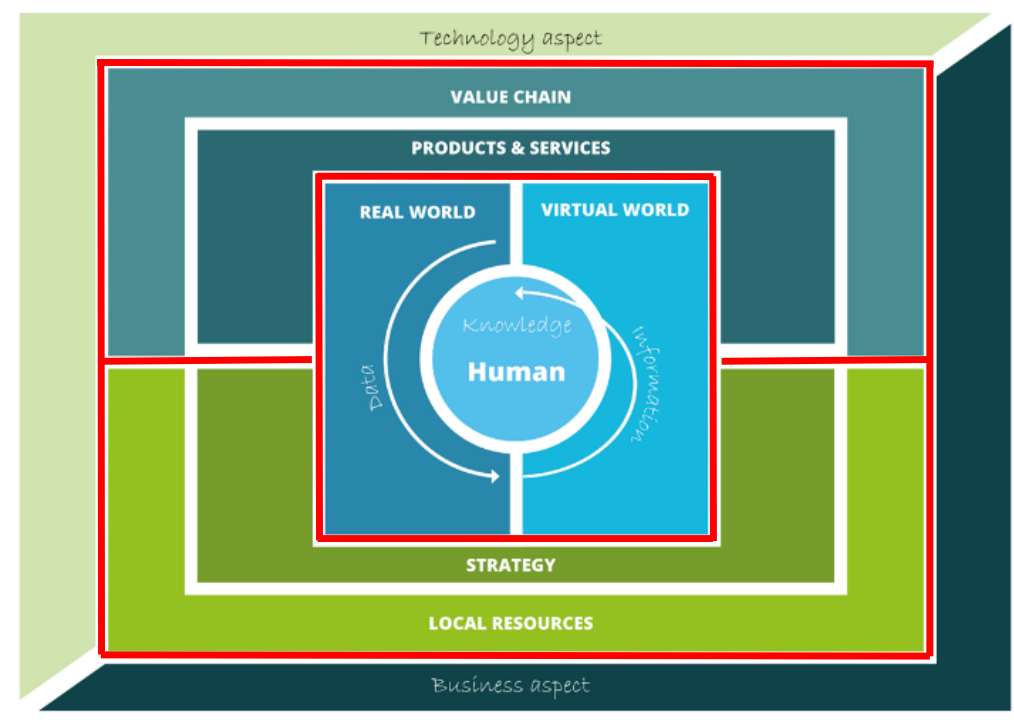

Figure 2: Structure of the model

\subsection{Ecosystem}

This pillar contains a group of questions on management and statistical data characterizing the Strategy of the company. Survey questions aimed at providing a comprehensive knowledge of the local environment are also included here.

In the Local resources dimension, the direct operating environment of the company and the peculiarities of the local market are examined. The issues addressed relate to relevant obstacles, available R\&D\&I services, appropriateness of existing infrastructure, and up-to-date info-communication technologies, as well.

In connection with territorial criteria, the companies are asked about how satisfied they are with the conditions of the business and the legal environment, institutional provision, and infrastructural developments. Other essential aspects involve the financial resources used to support the R\&D\&I activities and the extent to which these are applied. The model includes questions about the range of such services available in the local market in terms of quantity, quality, and price. The feasibility of environmental awareness and sustainable development raises the question of the company's attitude towards the conscious use of energy and materials, as well as their manufacturing methods.

In the Strategy dimension, the primary question is whether the company sees a link between its competitiveness and Industry 4.0 implementation, i.e., whether it understands that it is a topic that will improve its position in the market. For this end, the company needs to analyze and evaluate its current digital maturity and set clear goals for the period ahead. It is essential to identify the key areas and measures that will be paid off by the highest value generated. If such an accepted and documented strategy exists, it is worthwhile measuring the implementation of it with indicators. Organizational issues, including the availability of the necessary expert base, are also examined. Furthermore, the evaluation of parallel infrastructural developments, competitiveness preferences, R\&D efforts, and preferences are also relevant areas. Specifically, regarding the results of strategic decisions: development target areas, commissioning of tools and technologies that support sustainability are also investigated.

\subsection{Value Creation}

The physical resources needed to create value, the processes in the virtual world's sphere, and the characteristics of the human (who connects them all, and who is able to interpret the data and control the system) are also taken into account to assess the company's capabilities at the micro-level.

The dimension Real world is not only applicable to qualify the organization in terms of their Industry 4.0 readiness but also, in a broader sense, to highlight the strengths and weaknesses of their current market position. The existing equipment and future development directions, challenges, and opportunities of using cyber-physical production systems must also be evaluated. Regarding the application of new and digital trends, the present state and the role of technologies that have the most substantial connection to Industry 4.0 (Big Data, Al, loT, M2M communication, etc.) are examined. A question that comes to mind is, where is the biggest 
challenge regarding the implementation of technologies: in the research, development, standardization, or deployment phase? Robot density is an exact and internationally accepted indicator that is also included in the model. The qualitative and quantitative criteria of the tools available in logistics and manufacturing, as well as the relevant development ideas of the company, are addressed.

The questions in the dimension Virtual world consider the internal production and logistics processes and their characteristics. The issues addressed are the following: the areas of data collection, data processing methods, respondents' view on robotization and safety of cloud-based platforms, the implementation phase of the virtual environment.

In the Human dimension, the impact of robots on the labour market, changing human conditions, type of existing training programs, and the assessment method of employee competencies are also looked at.

\subsection{Value}

The characteristics of smart products and services and the customers, suppliers, and business partners closely associated with them are assessed in this third pillar. The hallmark of smart products is that they collect and transmit data about themselves during their product use phase. The question is whether the manufacturer utilizes these and, if so, precisely in which areas? How well are services based on usage data built into the company's knowledge base? These questions are investigated in the Products and services dimension.

The role of the Value chain dimension in terms of knowledge as added value provides an answer to where a company can position itself in global markets. From the number of partnerships, the responses received about the organization of the company and its operational philosophy decisive conclusions about both the horizontal and vertical integration as the basic features of Industry 4.0 can be made.

In terms of approach, it is relevant to what extent the company supports open innovation and whether they pursue active innovation management. A series of factors are examined like the territorial embeddedness of the company in the innovation ecosystem, the willingness to cooperate in R\&D\&l, the existence of cooperation with universities and research institutes, as well as with the actors of the economic sphere. In terms of horizontal integration, the local market players who can be accepted as suppliers, the level of trust networks that emerge, and the extent and direction of information sharing are essential aspects. Organizational philosophy, such as where the company sees its role in the supply chain and how dominant its added value produced, is also addressed.

The pillars and dimensions, their contents, and the number of questions connected to them are summarized in Table 1.

Table 1: Pillars and dimensions of the CCMS model

\begin{tabular}{llll}
\hline Pillar & Topics & Dimensions & Questions \\
\hline \multirow{2}{*}{ Ecosystem } & $\begin{array}{l}\text { Financial and statistical data } \\
\text { Local environment }\end{array}$ & $\begin{array}{l}\text { Local resources } \\
\text { Strategy }\end{array}$ & $27(29 \%)$ \\
\hline
\end{tabular}

\begin{tabular}{|c|c|c|c|}
\hline \multirow{4}{*}{$\begin{array}{l}\text { Value } \\
\text { Creation }\end{array}$} & \multicolumn{3}{|l|}{ Individual Industry 4.0 capabilities } \\
\hline & Physical resources for value creation & Real world & \\
\hline & Processes of the virtual world & Virtual world & $35(38 \%)$ \\
\hline & $\begin{array}{l}\text { The human who can interpret the data and control } \\
\text { the system }\end{array}$ & Human & \\
\hline Value & Smart products and services & Products and Services & $30(33 \%)$ \\
\hline & Customers, suppliers, and business partners & Value chain & \\
\hline
\end{tabular}




\section{Intervention points}

As mentioned, the most important output of the CCMS model is a list of prioritized intervention points that shows the company the fields where it should make changes to reach a higher maturity level. For each dimension, there are eight predefined intervention points: for the demonstration of the model approach and the structure of intervention points, the authors introduce here three of them (Local resources, Virtual world, and Human) in more detail, as examples. As the different fields of action are in close relation to each other, the intervention points are overlapping, and have common aspects in some cases.

\subsection{Local resources}

\section{Financial resources}

This intervention point considers the following factors: loans, tender opportunities, investor willingness, availability of venture capital, and the rate of resource utilization as a percentage of sales revenue.

\section{Environmental resources}

Environmental resources include legal regulation, availability of financial institutions' services, logistical and transport environment, and the commercial service provider environment.

\section{Resource challenges}

Challenges could be the widespread digital illiteracy, lack of skilled workforce, rising labour and logistics costs, shrinking market opportunities, and lack of R\&D\&I partners.

Infrastructural resources

Availability of technical service providers and the quality of the offered services are considered as infrastructural resources: for example, $5 \mathrm{G}$ availability, internet bandwidth, etc.

\section{Cooperation opportunities}

It is feasible to establish long-term relationships, for example, with R\&D\&I companies, universities (research and recruitment opportunities). Industrial parks, chambers, clusters, also help companies to exploit cooperation potentials.

\section{Matureness of attitude}

Corporate culture and public acceptance of vs. resistance to technological developments are also determining the companies' future and possible actions.

\section{Workforce availability}

Labor fluctuation, suction effect of other companies, and problems arising from the education system (e.g., no education institute in the area that could offer training in the respondent's industry area) are considered at this intervention point.

\section{Availability of value chain participants}

This point is affected by the following issues. First, the geographical availability of value chain members: are they close to the respondent's location, or the products/materials have to be transported from faraway? The platform where they can be reached is also crucial: e.g., via phone/email/corporate platform. This intervention point also has a connection with the digitalization level of the partners.

\subsection{Virtual world}

\section{Utilization of collected data}

Most of the companies analyze the collected data, but in some cases, although the collection is made, the data is only stored without using it. (Data collection methods, equipment, etc., are part of the Real world dimension). It also means two different levels of data processing if the data analysis is made by hand, or it is automated. The best case is when the collected data is automatically analyzed, decisions are made automatically based on them, and predictions are also made, for example, to support maintenance processes. 
Applied technologies

Application of Big Data, cloud technologies, ICT, the technology of data analysis, and the creation of virtual models from the production and logistic processes are considered here.

Automatic, adaptive control of production

The results of data analysis, simulation models, etc. should be tied back into the production processes. Interventions, changes should be made automatically based on them.

\section{Degree of automation}

The number of robots, areas of use (whether they are used for human-robot collaboration, assembly or movement tasks), and their re-programmability are essential aspects of Industry 4.0.

Digital mapping and intervention

Application of production and logistics system simulation, digital twins, are contributing significantly to the digitalization process. The usage of the results coming from these technologies is also carrying opportunities: they can be applied in layout planning (e.g., rearranging the factory), scheduling (e.g., using the simulation model for validating the scheduling plans).

Level of IT development and Vertical integration

Degree of digitalization in information exchange (emails, a corporate communication platform, or other), development of data storage technologies are included here. The update of the collected data could be done manually or automatically, as well. Version control issues, paperless documentation in manufacturing are also considered (electronic instructions, document circulation with digital signature).

\section{Visualization}

Visualization of data and digital models helps companies to see and understand their processes: e.g., interactive dashboards, a screen in the factory manager's office, and displays at the end of the production lines. Usage of virtual reality in the production (maintenance, picking tasks) could also improve effectiveness in production. Extensive usage of summary graphs in EIS (Executive Information System) and MIS (Management Information System) enables a quick overview and understanding of the critical processes by a glance.

IT security

Data integrity and authenticity, appropriate authentication methods, inviolability, obtained certificates are fundamental parts of a secure IT system. Different strategies exist: in some cases, it is possible to interfere in the production from outside the factory; in other cases, only production statistics can be queried.

\subsection{Human}

Position of the human in the production

Adaptability to rapid change, high learning speed are critical skills when applying new technologies in production.

\section{HR challenges}

Lack of necessary competencies, workforce availability, employees' readiness to adapt to changing work environment and circumstances, building an atmosphere to inspire individual initiatives, setting up a proper motivation system are challenges that the Human Resource departments have to face nowadays.

Working in the digital space

Working from home, applying Artificial Intelligence, using new digital solutions (e.g., smartphone, chat), working device dependency, and being able to learn to use them is crucial for employees.

\section{Education and training}

Investment in education, continuous registration of employee competence, skill matrix - based on this, personalized training programs could be created, and employees could work in a job that matches their qualifications. 


\section{Employee mobility}

How flexible they are in terms of the place of work, in space and time, how much they can work together in an international cultural environment. Family-friendly workplace, corporate kindergarten, and school, sports opportunities are also essential for employees and the image of the company.

\section{Workplace safety}

Employees have to follow new rules in a digitized work environment; IT security is crucial in the life of a company. "Traditional" safety instructions and regulations also have to be communicated in a new way

\section{Openness to new technologies}

Cutting-edge technologies could not be applied if the employees have not an open attitude to new technologies. There is also a difference between passive acceptance and active motivation to use smart solutions during work.

\section{Recruitment strategy}

Appropriate use of online interfaces for recruitment purposes (e.g., Google Analytics, Facebook statistics) to manage fluctuations. PR activity on digital platforms is essential these days. It is also useful to connect the prospective employees during their studies with, for example, competitions, dual and cooperative training programs.

\section{Evaluation method}

The CCMS model is operating as an online survey, whose results and graphs are generated promptly and automatically after completing the study. They are presented in an interactive dashboard, including statistical results derived from the responses (a screenshot from this can be seen in Figure 3). In Figure 3, a radar diagram presenting the intervention points connected to each dimension - the orange line is the baseline, the blue one is calculated from the responses.

The questionnaire has to be filled in regarding the current state of the company, and the answers in connection with intervention points (which are required fields of improvement included in the survey) are compared to a baseline determined by the model developers. The intervention points to be suggested from the given set are derived from the answers and the weights (fixed by model creators and hidden from the respondents) attached to them. The intervention points are also weighted in a predefined manner. The answer and intervention point weighting are based on the authors' project experiences, state-of-the-art model descriptions taken from the literature, and adapted to the specific characteristics of SMEs. The most important output of the model is a list of priority intervention points drawn upon the weights and the difference between the current company status and the baseline. These points are the areas the company should focus on in its immediate future actions.

It is important to note, as technology improves and experience with usage is gathered, the necessity could arise any time to formulate new or reworded questions or modify the weights to keep the model up to date. The model is prepared for these changes, and its continuous adaptation to the fast-changing world does not require a massive effort from the developers.

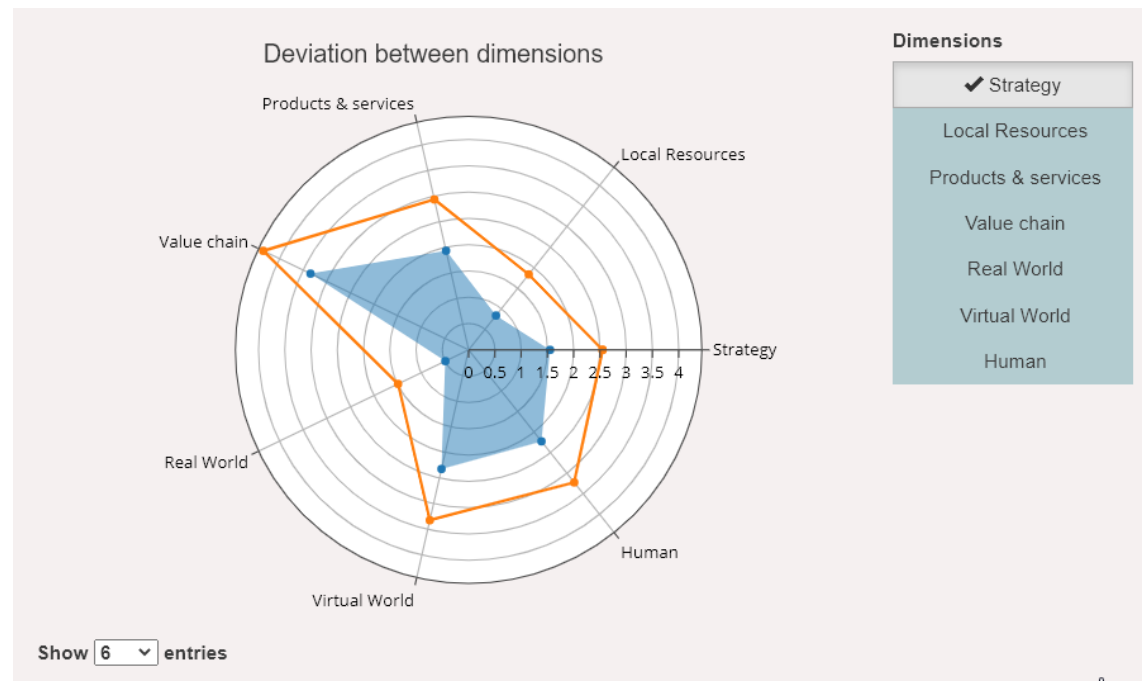

Figure 3: Interactive dashboard visualizing the results of CCMS model 


\section{Conclusions}

In this paper, a maturity model for manufacturing companies was outlined, which - built around a structured framework of pillars and dimensions - takes business and technological aspects into account, as well. CCMS focuses on a low-risk, quick overview of the company with an online survey, providing prompt results with the statistical analysis of the respondent's answers. Moreover, CCMS includes macro- and micro-level examination of the company, which helps decision-makers to determine the next steps in different fields, by creating a prioritized list of intervention points.

Applying the CCMS model gives a first overview of the company, and shows its as-is status. The output of the CCMS model is a priority list of the most crucial intervention points, which is determined on the basis of expert knowledge gained by literature synthesis, studying existing questionnaires, implementing surveys, and maturity models for the industry. This list may be used to derive a comprehensive strategic plan for the company on how to attain a higher maturity grade.

\section{Acknowledgement}

The research in this paper was supported by the European Commission through the H2020 project EPIC (https://www.centre-epic.eu/) under grant No. 739592.

\section{References}

Erol, S., Schumacher, A. and Sihn, W. (2016) "Strategic guidance towards Industry 4.0 - a three-stage process model", in Proceedings of International Conference on Competitive Manufacturing 2016 (COMA16), Stellenbosch, South Africa.

Fraunhofer Austria. Industrie 4.0 Reifegradmodell [Online]. Available at: https://www.fraunhofer.at/de/leistungen-fuer-unternehmen/industrie-4-0.html (Accessed: 09 June 2020)

IMPULS. Industry 4.0 Readiness Online Self-Check for Businesses [Online]. Available at: https://www.industrie40-readiness.de/?lang=en (Accessed: 09 June 2020)

Innovatioszentrum für Industrie 4.0. [Online]. Available at: https://www.i40.de/consulting/ (Accessed: 09 June 2020)

Leineweber, S., Wienbruch, T., Lins, D., Kreimeier, D. and Kuhlenkötter, B. (2018) “Concept for an evolutionary maturity based Industrie 4.0 migration model", Procedia CIRP, Vol. 72, pp. 404-409.

Leyh, C., Schäffer, T. and Forstenhäusler, S. (2016) „SIMMI 4.0 - Vorschlag eines Reifegradmodells zur Klassifikation der unternehmensweiten Anwendungssystemlandschaft mit Fokus Industrie 4.0", Dresden.

Marheine, C., Gruber, L. and Back, A. (2019) „Innovation durch den Einsatz von Enterprise loT-Lösungen: Ein Modell zur Bestimmung des Innovationspotenzials", HMD Praxis der Wirtschaftsinformatik, Vol. 56, pp. 11261143.

Mittal, S., Khan, M., Romero, D. and Wuest, T. (2018) "A Critical Review of Smart Manufacturing \& Industry 4.0 Maturity Models: Implications for Small and Medium-sized Enterprises (SMEs)", Journal of Manufacturing Systems, Vol. 49, pp. 194-214.

Nick, G., Gallina, V., Szaller, Á., Várgedő, T. and Schumacher, A. (2019a) "Industry 4.0 in Germany, Austria and Hungary: interpretation, strategies and readiness model", Proceedings of the16th IMEKO TC10 Conference, pp. 71-76.

Nick, G., Szaller, Á., Bergmann, J. and Várgedő, T. (2019b) “Industry 4.0 readiness in Hungary: model, and the first results in connection to data application", IFAC PapersOnline, Vol. 52, No. 13, pp. 289-294.

Puchan, J., Seif, H. and Mayer, D. (2015) Bestimmung des Stands deutscher produzierender Unternehmen auf dem Weg zu Industrie 4.0 und Verwendung der Ergebnisse für ein Industrie-4.0-Reifegradmodell. Lucerne: manaBuch, pp. 60-68.

Schuh, G., Anderl, R., Gausemeier, J., ten Hompel, M. and Wahlster, W. (Eds) (2017) Industrie 4.0 Maturity Index. Managing the Digital Transformation of Companies (acatech STUDY), Munich: Herbert Utz Verlag. VDMA and Partners (2016) Guideline Industrie 4.0 Guiding principles for the implementation of Industrie 4.0 in small and medium-sized businesses, Frankfurt am Main: VDMA Verlag. 